Atmos. Chem. Phys., 19, 14607-14620, 2019

https://doi.org/10.5194/acp-19-14607-2019

(C) Author(s) 2019. This work is distributed under

the Creative Commons Attribution 4.0 License.

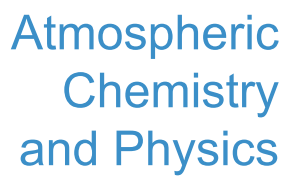

(c) (P)

\title{
Effects of water-soluble organic carbon on aerosol pH
}

\author{
Michael A. Battaglia Jr. ${ }^{1}$, Rodney J. Weber ${ }^{2}$, Athanasios Nenes ${ }^{2,3,4}$, and Christopher J. Hennigan ${ }^{1}$ \\ ${ }^{1}$ Department of Chemical, Biochemical and Environmental Engineering, University of Maryland, \\ Baltimore County, Baltimore, MD 21250, USA \\ ${ }^{2}$ School of Earth and Atmospheric Sciences, Georgia Institute of Technology, Atlanta, GA 30332, USA \\ ${ }^{3}$ Institute for Chemical Engineering Sciences, Foundation for Research and Technology - Hellas, Patras, 26504, Greece \\ ${ }^{4}$ Laboratory of Atmospheric Processes and their Impacts, School of Architecture, Civil and Environmental Engineering, \\ Ecole Polytechnique Fédérale de Lausanne, 1015, Lausanne, Switzerland
}

Correspondence: Christopher J. Hennigan (hennigan@umbc.edu)

Received: 9 April 2019 - Discussion started: 30 April 2019

Revised: 1 October 2019 - Accepted: 12 October 2019 - Published: 3 December 2019

\begin{abstract}
Water-soluble organic carbon (WSOC) is a ubiquitous and significant fraction of fine particulate matter. Despite advances in aerosol thermodynamic equilibrium models, there is limited understanding on the comprehensive impacts of WSOC on aerosol acidity $(\mathrm{pH})$. We address this limitation by studying submicron aerosols that represent the two extremes in acidity levels found in the atmosphere: strongly acidic aerosol from Baltimore, MD, and weakly acidic conditions characteristic of Beijing, China. These cases are then used to construct mixed inorganic-organic single-phase aqueous particles and thermodynamically analyzed by the Extended Aerosol Inorganics Model (E-AIM) and ISORROPIA models in combination with activity coefficient model AIOMFAC (Aerosol Inorganic-Organic Mixtures Functional groups Activity Coefficient) to evaluate the effects of WSOC on the $\mathrm{H}^{+}$ion activity coefficients $\left(\gamma_{\mathrm{H}^{+}}\right)$ and activity $(\mathrm{pH})$. We find that addition of organic acids and nonacid organic species concurrently increases $\gamma_{\mathrm{H}^{+}}$and aerosol liquid water. Under the highly acidic conditions typical of the eastern US (inorganic-only $\mathrm{pH} \sim 1$ ), these effects mostly offset each other, giving $\mathrm{pH}$ changes of $<0.5 \mathrm{pH}$ units even at organic aerosol dry mass fractions in excess of $60 \%$. Under conditions with weaker acidity typical of Beijing (inorganic-only $\mathrm{pH} \sim 4.5$ ), the nonacidic WSOC compounds had similarly minor effects on aerosol $\mathrm{pH}$, but organic acids imparted the largest changes in $\mathrm{pH}$ compared to the inorganic-only simulations. Organic acids affect $\mathrm{pH}$ in the order of their $\mathrm{p} K_{\mathrm{a}}$ values (oxalic acid $>$ malonic acid $>$ glutaric acid). Although the inorganic-only $\mathrm{pH}$ was above the $\mathrm{p} K_{\mathrm{a}}$ value of all three organic acids investigated, $\mathrm{pH}$
\end{abstract}

changes in excess of $1 \mathrm{pH}$ unit were only observed at unrealistic organic acid levels (aerosol organic acid concentrations $>35 \mu \mathrm{g} \mathrm{m}^{-3}$ ) in Beijing. The model simulations were run at $70 \%, 80 \%$, and $90 \%$ relative humidity (RH) levels and the effect of WSOC was inversely related to RH. At $90 \% \mathrm{RH}$, WSOC altered aerosol $\mathrm{pH}$ by up to $\sim 0.2 \mathrm{pH}$ units, though the effect was up to $\sim 0.6 \mathrm{pH}$ units at $70 \% \mathrm{RH}$. The somewhat offsetting nature of these effects suggests that aerosol $\mathrm{pH}$ is sufficiently constrained by the inorganic constituents alone under conditions where liquid-liquid phase separation is not anticipated to occur.

\section{Introduction}

The acidity of atmospheric particles plays a critical role in many physicochemical processes. Some of these processes include sulfur oxidation and halogen chemistry, with important implications for the formation of sulfates (Chameides, 1984); the oxidation of volatile organic compounds (VOCs) and ozone formation in marine environments (Keene et al., 1998); the gas-particle partitioning of many semivolatile species (Ahrens et al., 2012; Keene et al., 2004); and enhancements to secondary organic aerosol (SOA) formation (Hallquist et al., 2009). The inorganic salt constituents in atmospheric particles, such as ammonium sulfate $\left(\left(\mathrm{NH}_{4}\right)_{2} \mathrm{SO}_{4}\right)$ and ammonium bisulfate $\left(\mathrm{NH}_{4} \mathrm{HSO}_{4}\right)$, contribute to particle acidity and water content, with effects on aerosol radiative forcing (Seinfeld and Pandis, 2016). In addition to the physicochemical effects within particles, 
their bulk acidity can affect the health of both environmental ecosystems and the human populations therein either directly (Gwynn et al., 2000; Peters et al., 1996; Schindler, 1988; Spengler et al., 1996; Fang et al., 2017; Johnson et al., 2008) or by their effects on nutrient deposition (Myriokefalitakis et al., 2016, 2018; Kanakidou et al., 2016; Nenes et al., 2011).

$\mathrm{pH}$, the parameter serving to define and describe the acidity of aqueous solutions, often has no direct correlation with proxy measurement methods such as aerosol strong acidity $\left(\mathrm{H}^{+}\right.$contributed by strong acids that dissociated completely at any $\mathrm{pH}$ level) or aerosol total acidity (dissociated $\mathrm{H}^{+}$and undissociated $\mathrm{H}^{+}$bound to weak acids) (Hennigan et al., 2015; Song et al., 2018b). The most accurate predictions of aerosol $\mathrm{pH}$ come from aerosol thermodynamic equilibrium models constrained by both aerosol- and gas-phase measurements (i.e., forward mode calculations) or from the measured gas-particle partitioning of semivolatile species, including ammonia, nitric acid, or oxalic acid, which provide direct insight to $\mathrm{pH}$ (Hennigan et al., 2015). Both approaches utilize aerosol- and gas-phase composition measurements, along with the temperature and relative humidity $(\mathrm{RH})$, to obtain aerosol $\mathrm{pH}$ values. Consistent $\mathrm{pH}$ values are obtained when the assumptions about aerosol mixing and equilibrium are met (Guo et al., 2018a, b).

Different aerosol thermodynamic equilibrium models have been developed through the years, each with a unique set of assumptions, simplifications, and approach to obtain the composition at thermodynamic equilibrium. The Extended Aerosol Inorganics Model (E-AIM, http://www.aim. env.uea.ac.uk/aim/aim.php, last access: 28 September 2019) (Wexler and Clegg, 2002; Friese and Ebel, 2010) and the ISORROPIA-II model (Greek for "equilibrium", https: //www.epfl.ch/labs/lapi/isorropia/, last access: 28 September 2019) (Fountoukis and Nenes, 2007) are widely used to calculate aerosol $\mathrm{pH}$ for atmospheric and experimental particle distributions (Guo et al., 2015, 2016, 2017; Wang et al., 2016). The Aerosol Inorganic-Organic Mixtures Functional groups Activity Coefficient (AIOMFAC) model (http://www.aiomfac.caltech.edu/model.html, last access: 28 September 2019) offers the most extensive treatment of organic-inorganic interactions (Zuend et al., 2008, 2011) of models to date but is primarily an activity coefficient model that does not solve full thermodynamic equilibrium calculations or phase partitioning as E-AIM and ISORROPIA do. At present, E-AIM, ISORROPIA, and AIOMFAC are widely used for atmospheric applications due to their demonstrated predictive capabilities and their accessibility: they are freely available online and include resources and user guides to facilitate their application and use.

One key difference among the models is their treatment of organics. ISORROPIA does not include organic species. E-AIM functions similarly to ISORROPIA when considering inorganic species but in addition offers a limited library of organic acids (included by UNIFAC methods or fitted activity equations). AIOMFAC offers wide support for or- ganic components but is an activity coefficient model that does not solve the equilibrium partitioning calculations for which the other models were designed. While AIOMFAC has been used in combination with thermodynamic equilibrium models such as ISORROPIA-II (Pye et al., 2018), these are custom modifications to the models and not reflected in the online versions used in this study. These models, and most others, do not treat organics in a way that is comprehensive (that is, simultaneous consideration of activity coefficient calculations and thermodynamic equilibrium calculations). However, these simplified thermodynamic models do seem to capture the partitioning of inorganic species well, even when organic components are present in large quantities, which indicates that $\mathrm{pH}$ should be captured well (Guo et al., 2018a). An additional consideration between the models is their treatment of organic acids. E-AIM offers support for limited $(n=8)$ organic acid species and treats the dissociation equilibrium of organic acids. In contrast, AIOMFAC treats organic acids as nondissociating, a model difference that is discussed in detail below. Note that the ion dissociation equilibria of inorganic species ( $\mathrm{such}$ as $\mathrm{HSO}_{4}^{-} / \mathrm{SO}_{4}^{2-}$ ) are explicitly considered in the equilibrium calculations of all three models employed in this study.

The effects of water-soluble organic carbon (WSOC) on aerosol $\mathrm{pH}$ come through two primary means: dilution of the aqueous phase by aerosol liquid water associated with the organic fraction $\left(W_{\mathrm{o}}\right)$ and changes to the hydrogen ion activity coefficient and thus hydrogen ion activity in solution ( $\gamma_{\mathrm{H}^{+}}$and $a_{\mathrm{H}^{+}}$, respectively). The total contribution of organics to aerosol water can be as much as $30 \%-50 \%$ of total fine-particle aerosol water in the polluted Beijing winter haze events (Tan et al., 2018; Huang et al., 2014), 40\%$50 \%$ in the southeast United States (Nah et al., 2018; Guo et al., 2015), and the eastern Mediterranean (Bougiatioti et al., 2016). The effects of organics (soluble and insoluble) on aerosol $\mathrm{pH}$ under conditions of liquid-liquid phase separation (LLPS) are more complex (Dallemagne et al., 2016). Free $\mathrm{H}^{+}$ion is predicted to have increased association with $\mathrm{SO}_{4}^{2-}$ to form $\mathrm{HSO}_{4}^{-}$when organic compounds are in the same phase as inorganic ions, resulting in a $0.1 \mathrm{pH}$ unit increase in aerosol pH (Pye et al., 2018). The isolation of the organic components in a separate phase (LLPS condition) also alters the partitioning behavior of $\mathrm{NH}_{3}$, a critical component that contributes to aerosol $\mathrm{pH}$. The inclusion, or lack thereof, of organic compounds was predicted to have a greater effect on $\mathrm{NH}_{3}$ partitioning behavior than the inclusion, or lack thereof, of nonvolatile cations, nitrate, and chloride (Guo et al., 2018a). In addition to these effects, AIOMFAC predicts that any organic presence in the same phase with inorganic constituents drives free $\mathrm{H}^{+}$to increased association with sulfate to form bisulfate, a compound predicted to be more miscible with organics than $\mathrm{H}^{+}$ and small cations. AIOMFAC was used to show that the organic phase of liquid-liquid phase separated particles still contains a significant amount of inorganics, affecting the par- 
titioning medium by inclusion of the inorganic ions and their associated water, lowering the mole fraction and activity of organics, and shifting the gas-particle partitioning of organic compounds with $\mathrm{O}: \mathrm{C}>0.6$ (Pye et al., 2018). In the case where multiple phases do exist, there is anticipated to be a primarily organic (PO) and primarily inorganic (PI) phase, each of which contains $\mathrm{H}^{+}$in equilibrium with the other phase (Zuend and Seinfeld, 2012). In cases where the vast majority of inorganics are partitioned to the PI phase, the $\mathrm{pH}$ is not anticipated to change drastically, as $\mathrm{H}^{+}$is also required to be in equilibrium with the other phases, which may explain the results of Pye et al. (2018). In the case of phase separation where the PO phase contains considerable amounts of inorganic species, there exists the possibility of a PI phase with substantially altered $\mathrm{H}^{+}$activity and, therefore, the potential for substantially altered aerosol $\mathrm{pH}$ (e.g., Dallemagne et al., 2016). The present study avoids such complexity and instead considers mixed organic-inorganic particles present in a single aqueous phase.

Aerosol pH can also be directly affected by organic acids, whose dissociation produces $\mathrm{H}^{+}$ions in the particle aqueous phase. Carboxylic acids represent a highly abundant moiety in atmospheric organic aerosol (Yatavelli et al., 2015; Kawamura and Bikkina, 2016; Nah et al., 2018). Although these atmospheric organic acids are typically weaker acids with higher $\mathrm{p} K_{\mathrm{a}}$ values than common inorganic acids $\left(\mathrm{H}_{2} \mathrm{SO}_{4}\right.$ and $\mathrm{HNO}_{3}$ ), they may contribute to particle acidity in some environments (Trebs et al., 2005). However, this effect is not present in all environments and is constrained to situations where the $\mathrm{pH}$ is in the range of the $\mathrm{p} K_{\mathrm{a}}$ of the acid in question (Nah et al., 2018; Song et al., 2018b). As both organic acids and nonacid organic species are expected to be present, there are competing effects within the particle: dilution by the water fraction associated with organic constituents, direct acidification by the dissolution of organic acids, and the change in $\gamma_{\mathrm{H}^{+}}$by interactions with the additional species in solution.

Oxalic acid (measured as the oxalate ion) is often the most abundant carboxylic acid in atmospheric aerosols (Bikkina et al., 2015). Several studies utilized E-AIM Model IV to evaluate the effect of oxalic acid on particle acidity (Vasilakos et al., 2018; Song et al., 2018b). With inorganics similar in composition to that of Baltimore, conditions applied in this study, an increase of $25 \%-50 \%$ of oxalic acid compared to the base case had an insignificant effect on aerosol pH when only one liquid phase was present. Pye et al. (2018) utilized data from the Southern Oxidant and Aerosol Study (SOAS) in ISORROPIA and AIOMFAC to investigate the gas-particle partitioning of ammonia, water, and organic compounds, and how liquid-liquid phase separation (LLPS) in particles can affect aerosol $\mathrm{pH}$, predicting a $0.7 \mathrm{pH}$ unit increase when the organic fraction and its diluting effect was considered. Generally, aerosol processes are not affected by a $\mathrm{pH}$ change of this magnitude, except in the regions on the thermodynamic sigmoid curves of semivolatile species where partitioning is shown to vary greatly for small changes in $\mathrm{pH}$ (Nah et al., 2018; Guo et al., 2018b).

In this work, we explore the effects of WSOC on aerosol $\mathrm{pH}$ in a systematic way by utilizing inorganic data to construct combinations of single, aqueous-phase particulate compositions and utilizing aerosol thermodynamic models to investigate the effects of different WSOC species and concentrations on $\gamma_{\mathrm{H}^{+}}$and $a_{\mathrm{H}^{+}}$.

\section{Methods}

\subsection{Data}

Inorganic and meteorological data used for this study were reported in prior work. Briefly, data from Baltimore, MD, were taken from Battaglia et al. (2017) and include speciated inorganic $\mathrm{PM}_{2.5}$ concentrations, meteorological data, and gas-phase $\mathrm{NH}_{3}$ measurements. The data used as thermodynamic model inputs are summertime (July) averages based on 3 or 5 years of monitoring. All model inputs and outputs are available at https://knb.ecoinformatics.org/ (last access: 15 October 2019) (urn:uuid:ae58e5f1-fb13-4e9c-800beeb8bcb14d84).

Aerosol inorganic composition, gas-phase $\mathrm{NH}_{3}$ measurements, and meteorological parameters were obtained during a study of winter haze formation in Beijing, China, in 2015 (Wang et al., 2016). These data represent a contrast with Baltimore due to different source contributions, differences in $\mathrm{NH}_{3}$ concentrations, $T, \mathrm{RH}$, and inorganic aerosol levels. The inorganic $\mathrm{PM}_{2.5}$ concentrations, and averaged seasonal $T$ and $\mathrm{RH}$, along with $\mathrm{NH}_{3}$ gas concentration values were obtained as model-ready inputs of the Beijing winter haze data from Guo et al. (2018b), based on supplemental information from Wang et al. (2016).

\subsection{General approach}

The general approach to this study was to utilize the inorganic PM and $\mathrm{NH}_{3}$ data described above, in combination with various additional WSOC constituents, as inputs to aerosol thermodynamic equilibrium models to investigate the effects on model-predicted aerosol $\mathrm{pH}$ and $\gamma_{\mathrm{H}^{+}}$. Inorganic data were modeled in either E-AIM IV or ISORROPIA-II to obtain equilibrium concentrations of aerosol liquid water (ALW) along with all inorganic aerosol ionic species. Organic constituents were then added to this invariant inorganic matrix (assuming the added organic mass was at equilibrium), at identical $T$ and $\mathrm{RH}$, and the resulting particle compositions were modeled in AIOMFAC to obtain aerosol $\mathrm{H}^{+}$ion activity $\left(a_{\mathrm{H}^{+}}\right.$and $\left.\gamma_{\mathrm{H}^{+}}\right)$and thus aerosol $\mathrm{pH}$. The average inorganic composition, gas-phase $\mathrm{NH}_{3}$, and meteorological conditions were held approximately constant for each location, while WSOC composition and concentrations were systematically varied. A matrix was constructed to examine multiple combinations of the selected organic component 
Table 1. Summary of model runs performed for the study. Inorganic composition is invariant and taken from the sources provided. Organic components were added in factorial fashion.

\begin{tabular}{llllr}
\hline Location & Inorganic data & Inorganic equilibrium model & Organic components & No. of points \\
\hline Baltimore & Battaglia et al. (2017) & E-AIM Model IV & Organic acids & 1331 \\
Baltimore & Battaglia et al. (2017) & E-AIM Model IV & Nonacid organics & 1331 \\
Beijing & Guo et al. (2018b) & ISORROPIA 2.3 & Organic acids & 1331 \\
& & E-AIM Model IV & Nonacid organics & 1331 \\
Beijing & \multirow{2}{*}{ Guo et al. (2018b) } & ISORROPIA 2.3 & & \\
& & E-AIM Model IV & & \\
\hline
\end{tabular}

composition levels (factorial design), and their effects were evaluated on the basis of the organic-to-inorganic ratio (OIR) or organic mass fraction, both computed on a dry particle basis. This full factorial design consists of three factors for each acid or nonacid condition (the identity of each species), each with discrete possible values (air concentrations in $\mu \mathrm{g} \mathrm{m}^{-3}$ ), where the experiment incorporates all possible combinations of these values across all factors (Keppel, 1991). For each location, this resulted in a total of 7986 model simulations, with 1331 simulations run for both cases of organic compounds selected, and at each of three distinct RH levels, as described below. A summary of the models run for each location is shown in Table 1. The RH in all simulations was fixed at either $\sim 70 \%, \sim 80 \%$, or $\sim 90 \%$, with inorganic system inputs calculated and invariant at each RH level based on the initial input data from either Baltimore or Beijing to ensure deliquescence of inorganic aerosol particles, to understand the sensitivity of the model-predicted aerosol $\mathrm{pH}$ to changes in RH (ALW), and to avoid liquid-liquid phase separation as a potential cause of organic-influenced aerosol $\mathrm{pH}$ changes (Pye et al., 2018). For all of the results presented in this analysis, aerosol $\mathrm{pH}$ was computed as the negative base-10 logarithm of the hydrogen ion activity taken from the E-AIM or AIOMFAC output ( $\left.\mathrm{pH}=-\log _{10} a_{\mathrm{H}^{+}}\right)$on a molality basis.

\subsection{Organic constituents}

Water-soluble organic compounds were selected by broadly classifying them as organic acids or nonacid organics. Within each category, three individual species were selected based on their detection in atmospheric particles and their availability in the predefined list of AIOMFAC organic species available on the AIOMFAC web interface, or the ability to reasonably construct them using the functional groups approach of AIOMFAC. In addition, nonacid organics were selected from three different primary moiety groups from among the AIOMFAC standard species. Oxalic acid $\left(\mathrm{C}_{2} \mathrm{H}_{2} \mathrm{O}_{4} \mathrm{p} K_{a 1}=1.23, \mathrm{p} K_{a 2}=4.19\right)$ (Lide, 1994), glutaric acid $\left(\mathrm{C}_{5} \mathrm{H}_{8} \mathrm{O}_{4}, \mathrm{p} K_{a 1}=4.31, \mathrm{p} K_{a 2}=5.41\right)$ (Lide, 1994), and malonic acid $\left(\mathrm{C}_{3} \mathrm{H}_{3} \mathrm{O}_{4}, \mathrm{p} K_{a 1}=2.83\right.$, $\mathrm{p} K_{a 2}=5.69$ ) (Lide, 1994) were selected as the three dicarboxylic acid species. Levoglucosan $\left(\mathrm{C}_{6} \mathrm{H}_{10} \mathrm{O}_{5}\right)$, tetrahydrofuran $\left(\left(\mathrm{CH}_{2}\right)_{4} \mathrm{O}\right)$, and 2-methyltetrol (1-methylbutane- 1,2,3,4-tetrol, $\mathrm{C}_{5} \mathrm{H}_{12} \mathrm{O}_{4}$ ), three organic species observed in ambient aerosols, were selected as the nonacid WSOC species. Concentration levels were not constrained by observations but were instead selected to achieve similar organicto-inorganic mass ratios for each of the two geographic regions being considered. For Beijing, typical organic mass fractions can be on the order of $50 \%-70 \%$ of total aerosol mass (Zhou et al., 2018) and 20\%-60\% of total aerosol mass for continental midlatitude locations like Baltimore (Carlton et al., 2009). For each geographic region, 11 different concentrations were chosen for each WSOC compound (0$4 \mu \mathrm{g} \mathrm{m}^{-3}$ for Baltimore; $0-40 \mu \mathrm{g} \mathrm{m}^{-3}$ for Beijing) and combined in factorial fashion: each organic acid concentration level combination of the three organic acids was examined in combination with every other level of the remaining two and vice versa for the nonacid organic species. Combinations of organic acids and nonacid organic species were not explicitly considered here; only combinations of organic acids with organic acids or combinations of nonacids with nonacids were examined experimentally. All model inputs and outputs are available at https://knb.ecoinformatics.org/ (last access: 15 October 2019).

\subsection{Thermodynamic model input configuration and equilibrium model evaluations}

E-AIM Model IV provides thermodynamic equilibrium modeling of the $\mathrm{H}^{+}-\mathrm{NH}_{4}^{+}-\mathrm{Na}^{+}-\mathrm{SO}_{4}^{2-}-\mathrm{NO}_{3}^{-}-\mathrm{Cl}^{-}-\mathrm{H}_{2} \mathrm{O}$ system at temperatures from 263.15 to $330 \mathrm{~K}$ for subsaturated systems that contain $\mathrm{NH}_{4}^{+}$and $\mathrm{Cl}^{-}$, or $\mathrm{Na}^{+}$in combination with other ions (Friese and Ebel, 2010). Data for Baltimore and Beijing were formatted for E-AIM input in the following ways: average inorganic species concentrations $\left(\mu \mathrm{g} \mathrm{m}^{-3}\right)$ were converted to moles per cubic meter; the average daily temperature for the same period was used as the temperature input; and the relative humidity of the system was fixed (at $70 \%, 80 \%$, or $90 \%$ ) both to ensure the inorganic system was in a deliquesced state and because of the RH restrictions (subsaturated solution requirements, $\mathrm{RH}>0.6$ ) on E-AIM Model IV inputs. In addition to fixing system RH at $70 \%, 80 \%$, or $90 \%$, the aerosol metastable (solid precipitate formation disabled) mode was enforced on the model by disabling the formation of all solids in the 
model input matrix, according to the analysis and recommendation of Guo et al. (2018b, 2015). Crustal species $\left(\mathrm{Ca}^{2+}\right.$, $\mathrm{Mg}^{2+}, \mathrm{K}^{+}$) not supported by the model were not considered, and the persistent cation deficiency was corrected by the addition of $\mathrm{H}^{+}$to the system to ensure electroneutrality. The amount of $\mathrm{H}^{+}$added was a not-insignificant amount, comprising approximately $65 \%$ of the amount of $\mathrm{NH}_{4}^{+}$included in the model for Baltimore, but makes sense given the expected acidic nature of eastern US, sulfate-rich aerosols (Weber et al., 2016). For Beijing, a persistent anion deficiency was addressed by addition of $\mathrm{OH}^{-}$to the system to ensure electroneutrality. The amount of $\mathrm{OH}^{-}$added to the system for the Beijing case was 1 order of magnitude lower than the cation species but on the same order of magnitude and 4-7 times lower than any other anion except $\mathrm{Cl}^{-}$.

E-AIM offers support for certain organic acid species. For the Baltimore and Beijing simulations, the organic acid species were added directly to the E-AIM model inputs. In the case of organic acid model runs, factorial combinations of the organic acid species at $0.0,0.01,0.02,0.04,0.08$, $0.16,0.32,0.5,1,2$, and $4 \mu \mathrm{g} \mathrm{m}^{-3}$ (Baltimore) and $0.0,1$, $2,5,10,15,20,25,30,35$, and $40 \mu \mathrm{g} \mathrm{m}^{-3}$ (Beijing) and were input into the model after concentrations were converted $\left(\mathrm{mol} \mathrm{m}^{-3}\right)$. Formation of organic solids was also disabled as part of the metastable equilibrium condition. For the nonacid organics, the addition of the selected species to the E-AIM equilibrium calculation was not possible, and the model was run with the inorganic constituents only. E-AIM provides output of the aqueous species mole fractions and mole-fraction-based activity coefficients; this mole-fractionbased aerosol $\mathrm{pH}$ was converted to a molality-based aerosol $\mathrm{pH}$ utilizing known thermodynamic relations (Robinson and Stokes, 1965; Jia et al., 2018).

\subsection{ISORROPIA-II model input configuration and equilibrium model evaluations}

ISORROPIA-II provides thermodynamic equilibrium modeling for the $\mathrm{H}^{+}-\mathrm{NH}_{4}^{+}-\mathrm{Na}^{+}-\mathrm{SO}_{4}^{2-}-\mathrm{NO}_{3}^{-}$ $-\mathrm{Cl}^{-}-\mathrm{Ca}^{2+}-\mathrm{Mg}^{2+}-\mathrm{K}^{+}-\mathrm{H}_{2} \mathrm{O}$ system across a wide range of temperature and $\mathrm{RH}$ values without limitation based on the input composition (Fountoukis and Nenes, 2007). Data for Beijing were already formatted for use in ISORROPIA-II as described above (Guo et al., 2018b). The formation of solids in the model was disabled (leading to potential supersaturated aerosols, metastable mode operation), based on the justifications in previous studies (Guo et al., $2015,2018 b$ ) and to maintain consistency with the E-AIM model conditions. An initial model run was performed to verify that identical model outputs were obtained using the inputs of Guo et al. (2018b). For the purposes of this investigation, the $\mathrm{RH}$ value was changed from the Beijing average ambient value of $56 \%$ to $70 \%, 80 \%$, or $90 \%$, consistent with the model input for the Baltimore data for the same reasons discussed above. The Beijing average ambient temperature of $274.05 \mathrm{~K}$ was used in the Beijing inorganic model calculations with the three $\mathrm{RH}$ values.

\subsection{AIOMFAC model input configuration and equilibrium model evaluations}

E-AIM was utilized to determine the equilibrium composition of the inorganic aerosol, including the $\mathrm{NH}_{3}$ phase partitioning and the aerosol liquid water content. Outputs from EAIM were then used as inputs into AIOMFAC to characterize the organic effects on aerosol $\mathrm{H}^{+}$activity and $\gamma_{\mathrm{H}^{+}}$(Fig. 1), The E-AIM outputs (AIOMFAC inputs) were also checked for consistency with ISORROPIA to ensure that the applied model assumptions $\left(\mathrm{H}^{+}\right.$and $\mathrm{OH}^{-}$as balancing species to achieve electroneutrality) provided reasonable results.

The particle-phase outputs from the E-AIM model runs were used as inputs to AIOMFAC; however, this required significant adjustments to the format to fit the AIOMFAC model. AIOMFAC requires inorganic species inputs to be entered as ionic pairs (whole molecular species entered as a cation and anion pair) in order to guarantee electroneutrality. Therefore, the ionic species outputs of E-AIM were converted to molecular species inputs by assigning pairs and then performing a stoichiometric balance until all ions were accounted for (i.e., E-AIM $\mathrm{H}^{+}$and $\mathrm{SO}_{4}^{2-}$ being combined in stoichiometric fashion as $\mathrm{H}_{2} \mathrm{SO}_{4}$ with corresponding reductions in the pool of E-AIM H${ }^{+}$and $\mathrm{SO}_{4}^{2-}$ ). In the Baltimore case for the pure inorganic input (all organic species modeled at $0.0 \mu \mathrm{g} \mathrm{m}^{-3}$ concentration), E-AIM Model IV provided particle-phase output for the following ions: $\mathrm{H}^{+}, \mathrm{NH}_{4}^{+}$, $\mathrm{Na}^{+}, \mathrm{HSO}_{4}^{-}, \mathrm{SO}_{4}^{2-}, \mathrm{NO}_{3}^{-}$, and $\mathrm{OH}^{-}$. In order to format these concentrations for AIOMFAC-specific inputs (that is, to compute the necessary mole fraction format of molecular species in the aerosol), the ions were assigned in the following ways. First, all $\mathrm{SO}_{4}^{2-}$ was associated with $\mathrm{H}^{+}$for the $\mathrm{H}_{2} \mathrm{SO}_{4}$ pair in AIOMFAC. All $\mathrm{NO}_{3}^{-}$was associated with $\mathrm{Na}^{+}$for the $\mathrm{NaNO}_{3}$ pair. The remaining $\mathrm{Na}^{+}$was associated with $\mathrm{SO}_{4}^{2-}$, then $\mathrm{NH}_{4}^{+}$with $\mathrm{HSO}_{4}^{-}$, and the remaining $\mathrm{NH}_{4}^{+}$ with the remaining $\mathrm{SO}_{4}^{-}$. This allocation process proceeded similarly for the Beijing data. The selected species and order of allocation of the ionic species appears to be dependent solely on the user and a priori knowledge of which molecular species are likely to exist in the aerosol particle as the dissociated ionic species. The selection of species is unlikely to affect model outcomes, as this is simply a way to account for the ionic species present in the AIOMFAC model inputs, which require matched cation-anion pairs and are expected to be fully dissociated in the aqueous phase during model evaluation. The end result is a mixture of inorganic molecular species containing the full concentration values generated by E-AIM assumed to be dissociated within the aerosol where each functional group can contribute to species activity based on the AIOMFAC model paradigm; assignment of molecular species pairings is performed only on the basis of formatting specifically for the AIOMFAC model. The inorganic inputs 


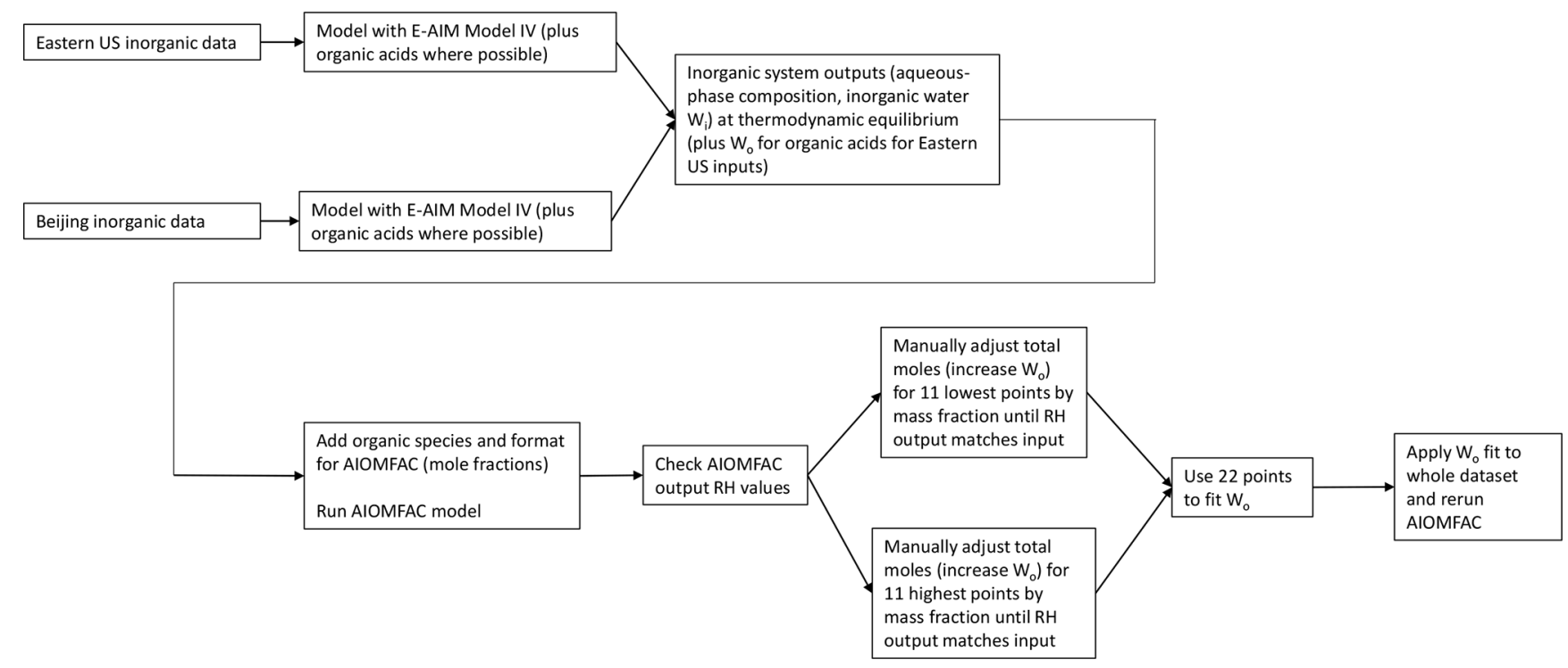

Figure 1. Flow diagram for adjusting total moles in the organic-inorganic mixed system inputs for the AIOMFAC model. Total moles were adjusted (representing increased $W_{\mathrm{o}}$ ) by the first 11 and last 11 model points until the AIOMFAC-output RH was within $5 \%$ of the fixed model input value $(70 \%, 80 \%$, or $90 \%)$. These 22 points were then used to fit a polynomial function to correct the total system moles for the remaining 1309 data points.

Table 2. Whole species inorganic inputs used in AIOMFAC modeling at 70\%, 80\%, or $90 \%$ RH. Inorganic equilibrium outputs were used to assign anions to cations to form whole species, represented here. Entries marked with a dash represent components not used for the given location as a result of the anion or cation not being present in the composition data (species not measured).

\begin{tabular}{lrrrrrr}
\hline Component & $\begin{array}{r}\text { Baltimore conc. } \\
\left(\mathrm{mol} \mathrm{m}^{-3}\right) \\
70 \% \mathrm{RH}\end{array}$ & $\begin{array}{r}\text { Baltimore conc. } \\
\left(\mathrm{mol} \mathrm{m}^{-3}\right) \\
80 \% \mathrm{RH}\end{array}$ & $\begin{array}{r}\text { Baltimore conc. } \\
\left(\mathrm{mol} \mathrm{m}^{-3}\right) \\
90 \% \mathrm{RH}\end{array}$ & $\begin{array}{r}\text { Beijing conc. } \\
\left(\mathrm{mol} \mathrm{m}^{-3}\right) \\
70 \% \mathrm{RH}\end{array}$ & $\begin{array}{r}\text { Beijing conc. } \\
\left(\mathrm{mol} \mathrm{m}^{-3}\right) \\
80 \% \mathrm{RH}\end{array}$ & $\begin{array}{r}\text { Beijing conc. } \\
\left(\mathrm{mol} \mathrm{m}^{-3}\right) \\
90 \% \mathrm{RH}\end{array}$ \\
\hline $\mathrm{H}_{2} \mathrm{SO}_{4}$ & $1.488 \times 10^{-10}$ & $2.418 \times 10^{-10}$ & $3.326 \times 10^{-10}$ & $3.13 \times 10^{-12}$ & $6.273 \times 10^{-12}$ & $1.010 \times 10^{-11}$ \\
$\mathrm{NH}_{4} \mathrm{HSO}_{4}$ & $3.460 \times 10^{-9}$ & $2.612 \times 10^{-9}$ & $1.899 \times 10^{-9}$ & $4.057 \times 10^{-11}$ & $3.173 \times 10^{-11}$ & $2.307 \times 10^{-11}$ \\
$\left(\mathrm{NH}_{4}\right)_{2} \mathrm{SO}_{4}$ & $2.395 \times 10^{-8}$ & $2.318 \times 10^{-8}$ & $2.425 \times 10^{-8}$ & $2.710 \times 10^{-7}$ & $2.710 \times 10^{-7}$ & $2.710 \times 10^{-7}$ \\
$\mathrm{NaNO}_{3}$ & $6.425 \times 10^{-11}$ & $1.207 \times 10^{-10}$ & $3.573 \times 10^{-10}$ & - & - & - \\
$\mathrm{Na}_{2} \mathrm{SO}_{4}$ & $1.403 \times 10^{-9}$ & $1.375 \times 10^{-9}$ & $1.257 \times 10^{-9}$ & - & - & - \\
$\mathrm{NH}_{4} \mathrm{Cl}$ & - & - & - & $4.793 \times 10^{-8}$ & $4.797 \times 10^{-8}$ & $4.799 \times 10^{-8}$ \\
$\mathrm{NH}_{4} \mathrm{NO}_{3}$ & - & - & - & $4.189 \times 10^{-7}$ & $4.189 \times 10^{-7}$ & $4.190 \times 10^{-7}$ \\
\hline
\end{tabular}

used in the AIOMFAC models for both Baltimore and Beijing simulations are given in Table 2.

An additional key step in formatting the E-AIM output for input to AIOMFAC is in the model treatment of the water associated with organic constituents, $W_{\mathrm{o}}$. E-AIM provided output of $W_{\mathrm{O}}$ as a part of the total aerosol liquid water (ALW; $W_{i}+W_{\mathrm{o}}$ ) for the organic acid simulations but provided no estimate of $W_{\mathrm{o}}$ for the nonacid simulations. $\mathrm{RH}$ is not an input to the AIOMFAC model runs. Rather, AIOMFAC requires the input of all species (inorganic and organic) in mole fractions and assumes the difference between the total inputs and unity is contributed by water, with water activity equal to the ambient relative humidity. Therefore, accounting for the water contributed by the organic species was an additional step in formatting the E-AIM outputs for AIOMFAC input as described below.

For two of the four cases (Baltimore and Beijing inorganics plus nonacid organics), $W_{\mathrm{o}}$ was added to the system by the following process, a flow diagram of which is shown in Fig. 1. For the first 11 points of the factorial design (representing the addition of only the first organic constituent at each concentration level) and the final 11 points of the factorial design (representing the 11 highest organic addition points, including the addition of all three organic species at their maximum selected concentration), total system moles were varied manually by increasing the inorganic model-predicted moles of aerosol water. AIOMFAC inputs (as mole fractions) were calculated using this adjusted total mole value. The 22 manually adjusted points were modeled 
in AIOMFAC. If the option for liquid water is selected (as it was in all of our simulations), AIOMFAC assumes that water makes up the difference between the mole or mass fraction of all inputs summed together and unity. To achieve consistency with the inorganic model results, the total moles of the system were manually adjusted until the RH output generated by the AIOMFAC model was within $\sim 5 \%$ of the $\mathrm{RH}$ value fixed for the inorganic systems. Once this close fit was achieved for the 22 selected points, they were used to generate polynomial fits of the total moles added to the system as $W_{\mathrm{o}}$ versus total organic mass (regardless of species). These polynomial fits were then applied to all model points to adjust the total system moles through the addition of liquid water associated with organic mass, resulting in AIOMFACpredicted RH values within $5 \%$ of the E-AIM RH values of $70 \%, 80 \%$, or $90 \%$. This method of accounting for $W_{\mathrm{o}}$ is a mathematical construct and does not reflect the use of a species-dependent organic hygroscopicity parameter, which would have been prohibitive to apply for each point across all cases and RH levels. Additionally, following the introduction of the adjusted $W_{\mathrm{o}}$ to the system, the gas phase was not allowed to re-equilibrate to the new water content contributed by the organic species. This provides a conservative (high) constraint on the effect of $W_{\mathrm{o}}$ (Guo et al., 2015).

\subsection{Evaluation of LLPS and accommodations for LLPS scenarios}

The $\mathrm{O}: \mathrm{C}$ ratio is a key factor that determines whether LLPS occurs in organic-containing particles (Song et al., 2018a; Freedman, 2017). We followed the parameterization found experimentally by Bertram et al. (2011) to evaluate the presence of LLPS in our simulations. This method uses the overall mixture $\mathrm{O}: \mathrm{C}$ ratio to determine the separation $\mathrm{RH}$ of the mixture. If the modeled (in this case, specified/enforced) system RH is lower than the parameterized separation $\mathrm{RH}$ ( $\mathrm{RH}_{\text {LLPS }}$ ), LLPS is likely to occur. This was performed for each of the nonacid mixtures for both Baltimore and Beijing data to verify the claim that LLPS was not anticipated to occur. For cases where the parameterized RHLLPS was higher than the predicted system RH, LLPS was anticipated to occur, and the point was flagged and excluded from further analysis. Out of 1331 simulations, Baltimore had $55 \%$ $(n=732), 70 \%(n=932)$, and $75 \%(n=998)$ simulations that met the non-LLPS criteria at $70 \%, 80 \%$, and $90 \% \mathrm{RH}$ respectively. Beijing had $85 \%(n=1131), 89 \%(n=1185)$, and $93 \%(n=1238)$ of simulations meet the non-LLPS conditions at $70 \%, 80 \%$, and $90 \% \mathrm{RH}$ respectively. Experimental work by You et al. (2013) indicates that glutaric acid, malonic acid, oxalic acid, or their mixtures do not undergo LLPS at any of the RHs investigated.

\section{Results and discussion}

\subsection{Effects of WSOC on aerosol $\gamma_{\mathrm{H}^{+}}$}

AIOMFAC-predicted aerosol $\mathrm{pH}$ and $\gamma_{\mathrm{H}^{+}}$versus the organic dry mass fraction (total mass of organics / sum of inorganics + organics, excluding ALW), along with aerosol liquid water used in the model evaluations for the nonacid species runs in Baltimore and Beijing at all RH levels, are shown in Figs. 2 and 3. For the case of nonacid WSOC compounds at $80 \%$ RH (Figs. $2 \mathrm{~d}$ and $3 \mathrm{~d}$ ), ALW increases from $4.7 \times 10^{-9}$ to $9.7 \times 10^{-9} \mathrm{~L} \mathrm{~m}^{-3}$ and from $9.6 \times 10^{-8}$ to $1.8 \times 10^{-7} \mathrm{~L} \mathrm{~m}^{-3}$ for Baltimore and Beijing, respectively, as the organic mass fraction increases. Similar trends follow for the $70 \%$ and $90 \%$ RH scenarios in both cities. This behavior makes sense, because the inorganic species concentrations and $\mathrm{RH}$ were fixed, so adding increasing levels of water-soluble organics increases the ALW. Increasing the organic dry mass fraction increases the value of $\gamma_{\mathrm{H}^{+}}$, from initial values of 0.10 and $0.16(80 \% \mathrm{RH})$ for Baltimore and Beijing under inorganiconly conditions to 2.4 for Baltimore (Fig. 2d) and 1.6 for Beijing (Fig. 3d). The higher absolute ALW levels in the Beijing simulations are due to the significantly higher inorganic and organic aerosol loadings.

The results follow for the additional RH values studied. For the case of nonacid organics at $70 \%$ RH (Figs. 2 and 3), increasing the organic dry mass fraction increases the value of $\gamma_{\mathrm{H}^{+}}$, from initial values of 0.11 and 0.18 for Baltimore and Beijing under inorganic-only conditions to 1.3 for Baltimore (at an organic dry mass fraction of 0.65 ) and 2.5 for Beijing (organic dry mass fraction of 0.67 ). ALW follows a similar trend at $70 \% \mathrm{RH}$ as it does at $80 \% \mathrm{RH}$, but with lower absolute levels. For the case of nonacid organics at $90 \% \mathrm{RH}$, increasing the organic dry mass fraction increases $\gamma_{\mathrm{H}^{+}}$, from initial values of 0.12 and 0.20 for Baltimore and Beijing under inorganic-only conditions to 1.2 for Baltimore (at an organic dry mass fraction of 0.79 ) and 0.78 for Beijing (organic dry mass fraction of 0.64). For these simulations, the ALW increases from $9.1 \times 10^{-9}$ to $2.4 \times 10^{-8} \mathrm{~L} \mathrm{~m}^{-3}$ and from $2.1 \times 10^{-7}$ to $3.6 \times 10^{-7} \mathrm{~L} \mathrm{~m}^{-3}$ for Baltimore and Beijing, respectively. In each case, the data plotted in Figs. 2 and 3 are those that are determined not to have LLPS according to the parameterization of Bertram et al. (2011).

The plots of ALW display distinct behaviors attributable to the way in which the water content was derived for the model systems. For the organic acid simulations, the ALW was taken directly from the E-AIM Model IV output of aqueous-phase water $\left(\mathrm{mol} \mathrm{m}^{-3}\right)$ run with inorganic and organic acid inputs. For all nonacid organic cases, total ALW $\left(W_{i}+W_{\mathrm{o}}\right)$ was determined according to the manual AIOMFAC output fitting/polynomial fit correlation described in the methods section (Fig. 1). This results in system water behavior described by polynomial fits of additional water versus organic dry mass fraction. 

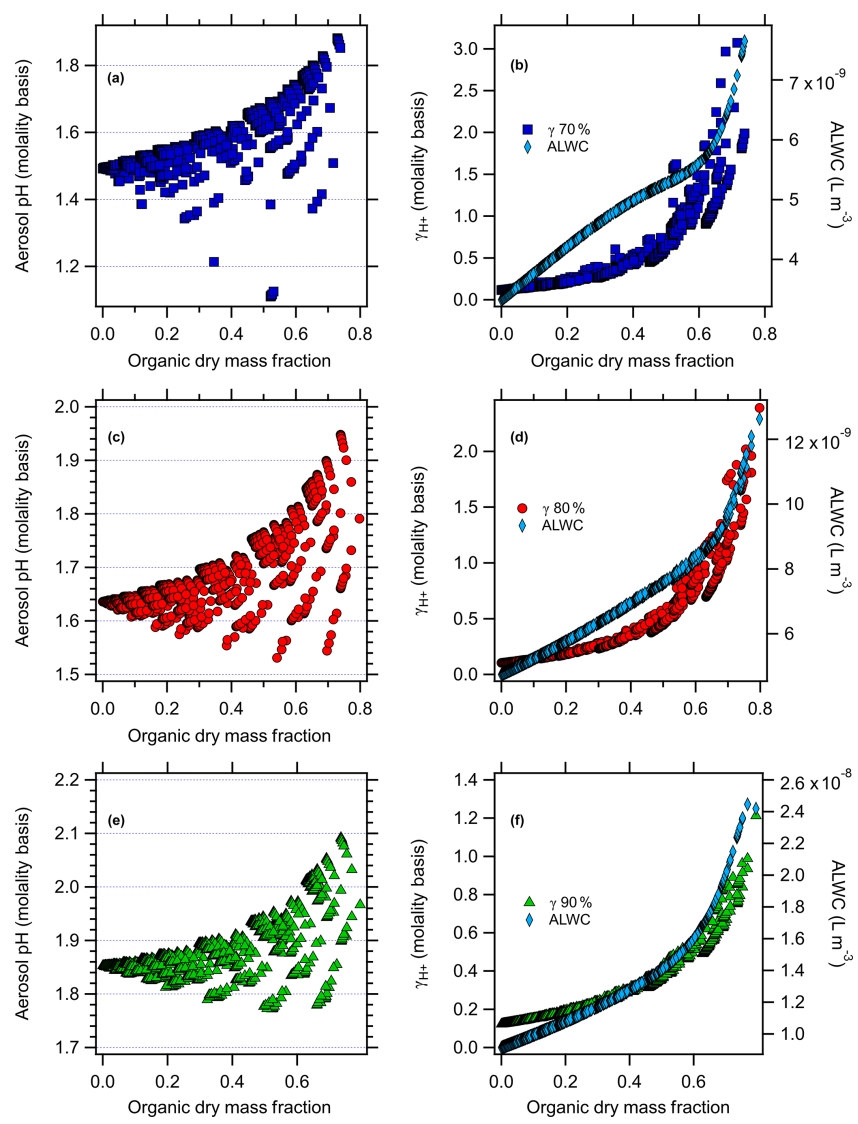

Figure 2. AIOMFAC-modeled aerosol pH (molality basis) versus organic dry mass fraction with the factorial addition of nonacid organic species and AIOMFAC-modeled $\gamma_{\mathrm{H}^{+}}$(molality basis) and aerosol liquid water (ALW, polynomial fit to AIOMFAC output) versus organic dry mass fraction (right panel) for Baltimore at (a, b) $70 \% \mathrm{RH},(\mathbf{c}, \mathbf{d}) 80 \% \mathrm{RH}$, and $(\mathbf{e}, \mathbf{f}) 90 \% \mathrm{RH}$.

\subsection{Effects of WSOC on aerosol pH}

The model-predicted effects of WSOC on aerosol $\mathrm{pH}$ are shown in Figs. 2-5. As the dry organic mass fraction increases, ALW increases as well, since the RH and inorganics are held constant. This suggests a diluting effect, which would increase $\mathrm{pH}$, in agreement with Guo et al. (2015). On the other hand, $\gamma_{\mathrm{H}^{+}}$also increases with increasing dry organic mass fraction, indicating that the addition of WSOC compounds increases the acidity (decreases $\mathrm{pH}$ ).

For the case of nonacid WSOC additions (Figs. 2 and 3), increasing the organic mass fraction decreases the predicted aerosol $\mathrm{pH}$ from the initial inorganic-only values from 1.64 to a max of 1.94 (Baltimore) and from 4.29 to a max of 4.38 (Beijing) at $80 \%$ RH. For the $70 \%$ RH simulations, the model predicted $\mathrm{pH}$ changes from 1.49 to a max of 1.88 for Baltimore and from 4.10 to a max of 4.33 for Beijing. For the $90 \% \mathrm{RH}$ case, the model predicted $\mathrm{pH}$ changes from 1.85 to a max of 2.09 for Baltimore and from 4.52 to a max of 4.56 for Beijing. The transition in the $\mathrm{pH}$ plots are smooth, where
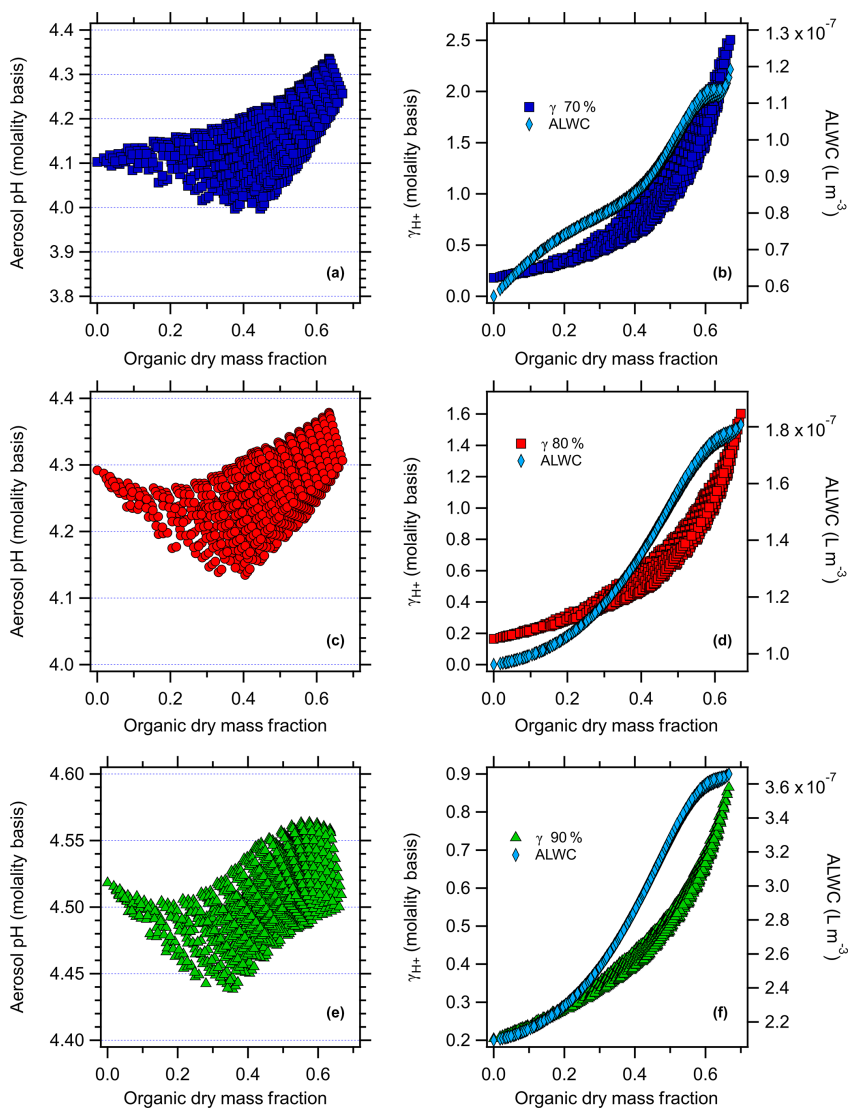

Figure 3. AIOMFAC-modeled aerosol $\mathrm{pH}$ (molality basis) versus organic dry mass fraction with the factorial addition of nonacid organic species and AIOMFAC-modeled $\gamma_{\mathrm{H}^{+}}$(molality basis) and aerosol liquid water (ALW, polynomial fit to AIOMFAC output) versus organic dry mass fraction (right panel) for Beijing at (a, b) $70 \% \mathrm{RH},(\mathbf{c}, \mathbf{d}) 80 \% \mathrm{RH}$, and (e, f) $90 \% \mathrm{RH}$.

the contour lines reflect individual levels of the factorial design and highlight the overall trend: as nonacidic WSOC is added, AIOMFAC-predicted aerosol $\mathrm{pH}$ increases for both the Baltimore and Beijing conditions. Since the WSOC leads to ALW uptake (diluting acidity), the increase in $\mathrm{pH}$ comes about due to the increase ALW having a stronger effect than the increase in $\gamma_{\mathrm{H}^{+}}$.

For the case of organic acids, increasing the organic mass fraction results in only slight changes in the predicted aerosol $\mathrm{pH}$ for Baltimore (Fig. 4) but more pronounced changes for Beijing (Fig. 5). At $80 \% \mathrm{RH}$, the predicted $\mathrm{pH}$ ranges from an initial (inorganic-only) value of 1.49 (Baltimore) and 4.2 (Beijing) to 1.34 and 2.6, respectively (total range $=0.4$ and $1.68 \mathrm{pH}$ units respectively). Similarly, there is a change from 1.33 to 1.22 (range $=0.34 \mathrm{pH}$ units) for Baltimore and a change from 4.06 to 2.52 (range $=1.58 \mathrm{pH}$ units) for the Beijing simulations at $70 \% \mathrm{RH}$. Finally, there is a change from 1.75 to 1.54 (range $=0.47$ ) for Baltimore and a change from 4.44 to 2.68 (range $=1.78$ ) for Beijing at $90 \% \mathrm{RH}$. The ranges represent the total range spread from the highest 

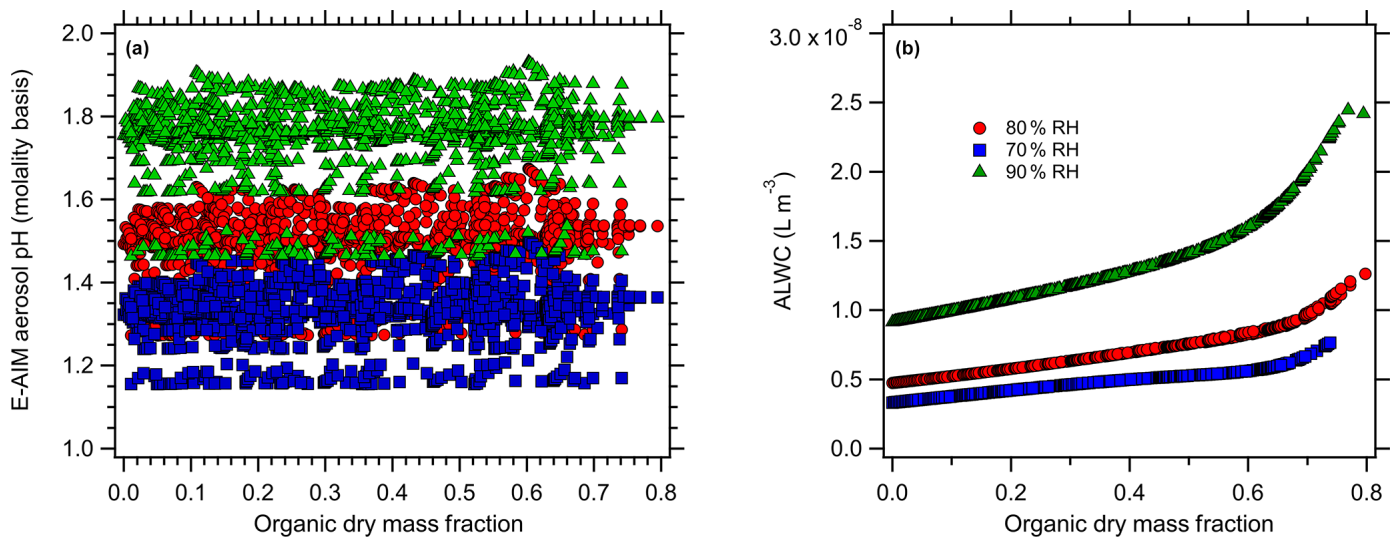

Figure 4. E-AIM-modeled (a) aerosol pH (molality basis) and (b) ALW at $70 \%$ (blue), $80 \%$ (red), and $90 \%$ RH (green) levels for the Baltimore simulations with organic acids.
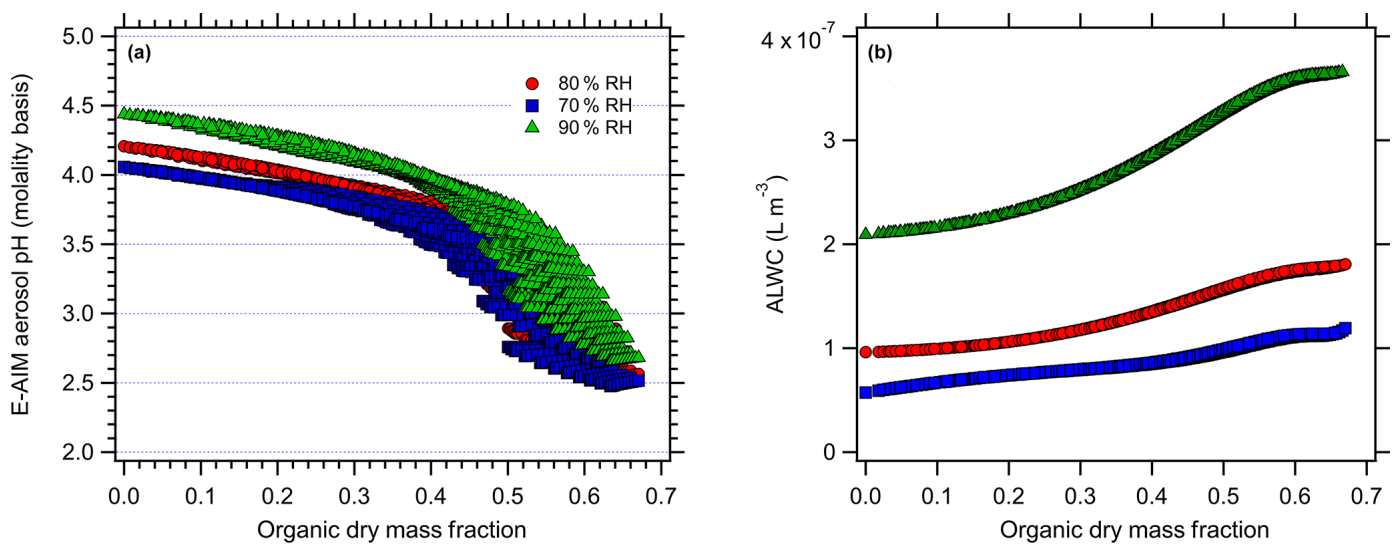

Figure 5. E-AIM-modeled (a) aerosol pH (molality basis) and (b) ALW at $70 \%$ (blue), $80 \%$ (red), and $90 \%$ RH (green) levels for the Beijing simulations with organic acids.

to lowest model-predicted $\mathrm{pH}$. For Baltimore, organic acids are predicted to have only a slight effect on aerosol $\mathrm{pH}$. Under the highly acidic conditions typical of the eastern US (inorganic-only $\mathrm{pH} \sim 1$ ), $\mathrm{pH}$ changes are always $<0.5 \mathrm{pH}$ units, even when the dry organic aerosol mass fraction exceeds $60 \%$ (corresponding to total aerosol organic acid concentrations up to $12 \mu \mathrm{g} \mathrm{m}^{-3}$ ). This is likely due to the $\mathrm{pH}$ being sufficiently acidic that the organic acid dissociation is largely inhibited. The undissociated organic acids still contribute ALW and affect $\gamma_{\mathrm{H}^{+}}$, but the combined effects produce very minor modifications to $\mathrm{pH}$. For Beijing, aerosol $\mathrm{pH}$ changes are predicted to be me more substantial with the addition of organic acids, due to the initially higher aerosol $\mathrm{pH}$. As organic acids are added, they can dissociate and contribute free $\mathrm{H}^{+}$. However, $\mathrm{pH}$ changes in excess of $1 \mathrm{pH}$ unit only occur at dry organic mass fractions $>0.5$. Given the high inorganic aerosol concentrations in Beijing, such $\mathrm{pH}$ changes in excess of $1 \mathrm{pH}$ unit correspond to unrealistically high aerosol organic acid mass concentrations $\left(>35 \mu \mathrm{g} \mathrm{m}^{-3}\right)$. The relatively minor effect of organic acids on aerosol $\mathrm{pH}$ in
Beijing is partly due to the high concentrations of ammonia (the sum of $\mathrm{NH}_{3}$ and $\mathrm{NH}_{4}^{+}$in Beijing $=32.8 \mu \mathrm{g} \mathrm{m}^{-3}$ ), which also contribute to the much higher inorganics-only $\mathrm{pH}$ compared to the eastern US conditions.

The effect of organic acids on $\mathrm{pH}$ is closely tied to acid strength (i.e., $\mathrm{p} K_{\mathrm{a}}$ value). Figure 6 shows that organic acids affect $\mathrm{pH}$ in the order of their $\mathrm{p} K_{\mathrm{a}}$ values, with oxalic acid $\left(\mathrm{p} K_{a 1}=1.23\right)>$ malonic acid $\left(\mathrm{p} K_{a 1}=2.83\right)>$ glutaric acid $\left(\mathrm{p} K_{a 1}=4.31\right)($ Lide, 1994). The simulations with a single organic acid demonstrate this effect most clearly: addition of $40 \mu \mathrm{g} \mathrm{m}^{-3}$ oxalic, malonic, and glutaric acid produce $\mathrm{pH}$ changes of $-1.3,-0.5$, and $-0.2 \mathrm{pH}$ units, respectively. The $\mathrm{pH}$ changes are all negative, indicating that the organic acids have increased particle acidity $\left(\mathrm{H}^{+}\right)$. Note that although the molar amounts added are not equivalent, the observed $\mathrm{pH}$ changes represent log-scale changes to the $\mathrm{H}^{+}$activity and the effect does proceed in the order of acid strength.

The magnitudes of these observed $\mathrm{pH}$ changes, with the exception of the Beijing organic acids case at high organic mass fractions ( $>35 \mu \mathrm{g} \mathrm{m}^{-3}$ acids concentration), are not ex- 

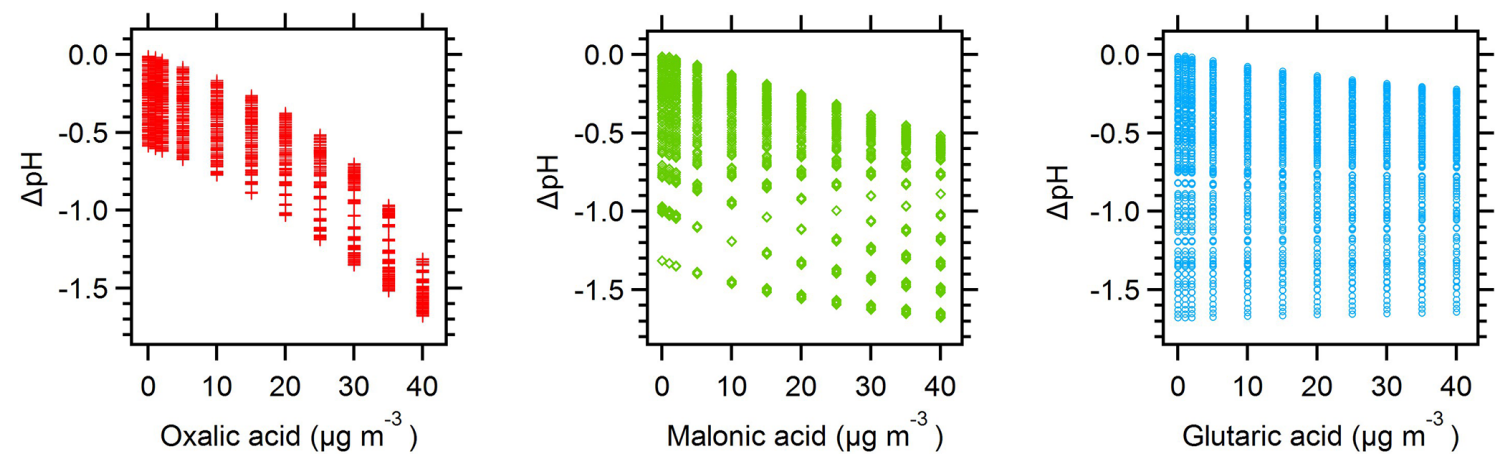

Figure 6. $\Delta \mathrm{pH}$ vs. discrete organic acid levels for the organic acid $\mathrm{pH}$ calculations carried out in E-AIM for Baltimore and Beijing. $\Delta \mathrm{pH}$ represents the difference between the initial inorganic-only $\mathrm{pH}$ prediction and all other model evaluations where organic acids were present.

pected to significantly alter particle conditions or lead to substantial changes in particle chemistry. For example, $\sim 0.5 \mathrm{pH}$ unit changes should not significantly alter IEPOX uptake (Xu et al., 2015) or metal dissolution (Fang et al., 2017), two processes affected by particle acidity. An exception would be conditions where the $\mathrm{pH}$ is close to the point where a given species is almost equally partitioned between the gas and particle phases (i.e., on the center/vertical portion of the titration-style sigmoid curves). This effect is demonstrated in the work of Guo et al. (2018b) and Vasilakos et al. (2018): when the $\mathrm{pH}$ lays on or near the inflection point of the sigmoid curve, a change of $0.5 \mathrm{pH}$ units can have a significant effect on species partitioning; however, when the $\mathrm{pH}$ is in the flatter regions of the curve above or below the rapid transitional region, a change of $0.5 \mathrm{pH}$ units will have a negligible effect on partitioning and thus particle chemistry.

Taken together, these results indicate that, despite organic mass fractions greater than $60 \%$ (dry particle mass basis), the combined effects of WSOC species on model-predicted aerosol $\mathrm{pH}$ is only about $0.5 \mathrm{pH}$ units, maximum, with most $\mathrm{pH}$ changes $<0.2 \mathrm{pH}$ units. This result is observed for nonacidic WSOC species and realistic concentrations of organic acids, as well as for simulations with a single organic compound added or for mixtures (Table 2). This suggests that the overall effect of WSOC on aerosol $\mathrm{pH}$ is quite minimal in conditions where LLPS does not occur. This finding holds only for systems in which there is no LLPS and the solvent is $\mathrm{H}_{2} \mathrm{O}$. For systems in which LLPS does occur, a condition expected in systems with $\mathrm{O}: \mathrm{C}$ ratio of the organic material $\leq 0.5$, or $\mathrm{RH}<60 \%$ with organic-sulfate mass ratio < 1 (Bertram et al., 2011; You et al., 2013), the situation becomes more complicated. As LLPS scenarios still require equilibrium between both predominantly aqueous and predominately organic phases, there are both water and inorganic ions (including $\mathrm{H}^{+}$) in the organic phase and organics in the inorganic-rich aqueous phase (Zuend and Seinfeld, 2012; Pye et al., 2018). Thus the IUPAC definition of $\mathrm{pH}$ could be applied to either phase so long as $\mathrm{H}^{+}$activity could be defined, necessitating an understanding of if and when
LLPS occurs, as well as the phase for which $\mathrm{pH}$ is being reported.

This work stands apart from but connects to related works. Pye et al. (2018) specifically examined the effects of LLPS, but the present study examines a different particle regime altogether (single aqueous phase with water, inorganics, and organics); instances where LLPSs were predicted to occur were excluded from the analysis for this reason.

Our findings are supported by the work of Song et al. (2018b), who utilized E-AIM Model IV and ISORROPIA to model the same Beijing winter haze conditions and found that addition of oxalic acid (set at $20 \%$ of the sulfate concentration) to their model in E-AIM produced reductions in $\mathrm{pH}$ of only $0.07 \mathrm{pH}$ units. Our results are also consistent with those of Vasilakos et al. (2018), who observed a similarly minor effect of oxalate addition on aerosol $\mathrm{pH}$ in the eastern US, and (Nah et al., 2018), where oxalic acid/oxalate gas-particle partitioning predicted without considering organic species in the thermodynamic analysis was in reasonable agreement with measurements. Our results indicate that additions of weaker organic acids, even at higher concentrations, would have even less of an effect on $\mathrm{pH}$.

A limitation of this study is that the model simulations were only run at three RH levels $(70 \%, 80 \%$, and $90 \%)$, with metastable conditions enforced at all times. However, aerosol particles progress through a wider RH range in the atmosphere, with concomitant effects on aerosol liquid water and phase transitions. Future work would need to expand on the $\mathrm{RH}$ range in order to elucidate the behavior as the system transitions from the LLPS condition to the fully mixed aqueous condition, as well as the contribution of changing ALW. Additionally, the use of E-AIM Model IV imposes composition limitations on the inputs (i.e., no support for $\mathrm{Ca}^{2+}$, $\mathrm{Mg}^{2+}$, or $\mathrm{K}^{+}$; limited support for $\mathrm{Na}^{+}$in the presence of $\mathrm{NH}_{4}^{+}$and $\mathrm{Cl}^{-}$), necessitating the use of equivalent cations to maintain electroneutrality in the model inputs. Combined with the use of metastable calculations, there exists a potential source of error in the solution activity if these species are considered and allowed to precipitate out in the thermo- 
dynamic model calculations (e.g., $\mathrm{CaSO}_{4}$ ). As AIOMFAC relies on specific, uniquely defined functional group interactions in the composition of activity coefficients, the exchange of an unsupported cation in E-AIM for a charge-equivalent cation may have effects on the output unknown to us carried through to the calculation of the species activity coefficients in AIOMFAC; this is a limitation of thermodynamic models that has been previously discussed (Jacobson, 1999; Kim and Seinfeld, 1995).

Another limitation of this study is consideration of only six WSOC species, despite hundreds or thousands being present in atmospheric particles. This is a limitation we acknowledge but is based on the significant number of model runs given the factorial design paradigm, as well as the decision to utilize only compounds predefined in the thermodynamic models (particularly the AIOMFAC model, which allows users to create organic molecules by combining subgroups). Because the compounds selected here have relatively low molecular weight (MW), it is possible that higher MW compounds, such as humic-like substances (HULIS), may impart a different effect. However, given the consistent results found here for both Baltimore and Beijing conditions across the $70 \%-$ $90 \%$ RH range, and at organic dry mass fractions that range from $0 \%$ to $60 \%$ utilizing WSOC containing four moieties, we feel our results do represent conditions in atmospheric particles. Future studies would be necessary to expand the selection of WSOC compounds and thus broaden the results reported here. Because we have forced the metastable mode on our use of the models, the system mixing state becomes another potential source of error. Here we have considered only internally mixed aerosol particles without LLPS, a case that may not exist given the concentration of organic species utilized in the model study; formation of solid precipitates may occur, which has the potential to drastically alter the aqueous phase activity values. The most significant restriction of this study is the lack of observational data for comparison. Direct measurements of particle $\mathrm{pH}$ have so far been restricted to simple laboratory particles of specific supermicron sizes and compositions (Rindelaub et al., 2016).

\section{Conclusions and implications}

In this work, the effects of WSOC on model-predicted aerosol $\mathrm{pH}$ were evaluated. Different inorganic datasets from Baltimore and Beijing winter haze conditions representing distinct inorganic composition regimes were first modeled in aerosol thermodynamic equilibrium models (E-AIM or ISORROPIA) and then combined with six different organic species in AIOMFAC to determine the effects on aqueousphase $\gamma_{\mathrm{H}^{+}}$and $a_{\mathrm{H}^{+}}$. We find that the effects of nonacid WSOC species to each of the regions have only a modest effect on aerosol $\mathrm{pH}(<0.5 \mathrm{pH}$ units, with most $<0.2 \mathrm{pH}$ units $)$. These small effects on $\mathrm{pH}$ were predicted even up to organic dry mass in excess of $60 \%$. Organic acids are predicted to have a similarly small effect on $\mathrm{pH}$ in the eastern US. In Beijing, organic acids can have larger effects on $\mathrm{pH}$ (in excess of $2 \mathrm{pH}$ units) but require stronger organic acids ( $\mathrm{p} K_{\mathrm{a}}$ values lower than the inorganic-only $\mathrm{pH}$ ) present at high concentrations, on the same order of molar concentration as the dissociating inorganic species. The magnitude of these changes to aerosol $\mathrm{pH}$ is consistent with the results predicted by previous studies that considered only inorganic aerosol components combined with a priori knowledge of organic mass, organic water contribution, and organic species hygroscopicity (Guo et al., 2015; Bougiatioti et al., 2016).

The results of this study have important implications for the aerosol modeling community as well as for experimental studies that utilize phase partitioning data to constrain aerosol $\mathrm{pH}$. Previous studies have postulated on the effect of organic species while ignoring their inclusion, or included them in order to elucidate the effects of LLPS, but this study demonstrates that, in the case of single-phase systems, including these species may only contribute unnecessary complexity to the model runs. As their effects are predominantly $<0.5 \mathrm{pH}$ units, it is not expected that the inclusion of organics will cause the $\mathrm{pH}$ of the system to reach any significant transitions unless the organic components have already driven the system to a sensitive portion of the species partitioning sigmoid curves, or aerosols in which there is significant phase separation. This work demonstrates that inclusion of large quantities of organic components does not appear to have a significant effect on model-predicted aerosol $\mathrm{pH}$, consistent with the findings of Guo et al. (2018a) and Vasilakos et al. (2018). Based on the species and concentrations of the organics studied here, future aerosol modeling studies carried out under conditions where LLPS is not occurring may be justified in the use of inorganic-only aerosol thermodynamic equilibrium models to predict aerosol $\mathrm{pH}$ without the direct inclusion of organic species.

Data availability. All model inputs and outputs are available at https://knb.ecoinformatics.org/ (urn:uuid:ae58e5f1-fb13-4e9c800b-eeb8bcb14d84) (Hennigan and Battaglia, 2019).

Author contributions. $\mathrm{CH}$ and $\mathrm{MB}$ devised the study. $\mathrm{MB}$ performed all modeling analyses. $\mathrm{CH}, \mathrm{MB}, \mathrm{RW}$, and $\mathrm{AN}$ collaborated on interpreting the results. MB prepared the manuscript, with significant contributions from $\mathrm{CH}, \mathrm{RW}$, and $\mathrm{AN}$.

Competing interests. The authors declare that they have no conflict of interest.

Acknowledgements. Michael A. Battaglia Jr. and Christopher J. Hennigan were supported by NSF grant no. CHE-1454763. Athanasios Nenes acknowledges support from the project PyroTRACH (ERC-2016-COG) funded from H2020-EU.1.1. - 
Excellent Science - European Research Council (ERC), project ID 726165. Rodney J. Weber recognizes support from the US EPA under STAR grant 835882. It is noted that the results of this research have not been formally reviewed by the EPA and the views expressed in this document are solely those of the authors and do not necessarily reflect those of the EPA. The EPA does not endorse any products or commercial services mentioned in this publication.

Financial support. This research has been supported by the National Science Foundation, Directorate for Mathematical and Physical Sciences (grant no. CHE-1454763); the European Research Council (grant no. PyroTRACH (726165)); and the US EPA (grant no. 835882).

Review statement. This paper was edited by Alexander Laskin and reviewed by two anonymous referees.

\section{References}

Ahrens, L., Harner, T., Shoeib, M., Lane, D. A., and Murphy, J. G.: Improved characterization of gas-particle partitioning for perand polyfluoroalkyl substances in the atmosphere using annular diffusion denuder samplers, Environ. Sci. Technol., 46, 71997206, https://doi.org/10.1021/es300898s, 2012.

Battaglia, M. A., Douglas, S., and Hennigan, C. J.: Effect of the Urban Heat Island on Aerosol pH, Environ. Sci. Technol., 51, 13095-13103, https://doi.org/10.1021/acs.est.7b02786, 2017.

Bertram, A. K., Martin, S. T., Hanna, S. J., Smith, M. L., Bodsworth, A., Chen, Q., Kuwata, M., Liu, A., You, Y., and Zorn, S. R.: Predicting the relative humidities of liquid-liquid phase separation, efflorescence, and deliquescence of mixed particles of ammonium sulfate, organic material, and water using the organic-to-sulfate mass ratio of the particle and the oxygen-tocarbon elemental ratio of the organic component, Atmos. Chem. Phys., 11, 10995-11006, https://doi.org/10.5194/acp-11-109952011, 2011.

Bikkina, S., Kawamura, K., and Miyazaki, Y.: Latitudinal distributions of atmospheric dicarboxylic acids, oxocarboxylic acids, and -dicarbonyls over the western North Pacific: Sources and formation pathways, J. Geophys. Res.-Atmos., 120, 5010-5035, https://doi.org/10.1002/2014jd022235, 2015.

Bougiatioti, A., Nikolaou, P., Stavroulas, I., Kouvarakis, G., Weber, R., Nenes, A., Kanakidou, M., and Mihalopoulos, N.: Particle water and $\mathrm{pH}$ in the eastern Mediterranean: source variability and implications for nutrient availability, Atmos. Chem. Phys., 16, 4579-4591, https://doi.org/10.5194/acp-16-4579-2016, 2016.

Carlton, A. G., Wiedinmyer, C., and Kroll, J. H.: A review of Secondary Organic Aerosol (SOA) formation from isoprene, Atmos. Chem. Phys., 9, 4987-5005, https://doi.org/10.5194/acp-9-49872009, 2009.

Chameides, W. L.: The Photochemistry of a Remote Marine Stratiform Cloud, J. Geophys. Res.-Atmos., 89, 4739-4755, https://doi.org/10.1029/JD089iD03p04739, 1984.

Dallemagne, M. A., Huang, X. Y., and Eddingsaas, N. C.: Variation in $\mathrm{pH}$ of Model Secondary Organic Aerosol during Liquid-
Liquid Phase Separation, J. Phys. Chem. A, 120, 2868-2876, https://doi.org/10.1021/acs.jpca.6b00275, 2016.

Fang, T., Guo, H. Y., Zeng, L. H., Verma, V., Nenes, A., and Weber, R. J.: Highly Acidic Ambient Particles, Soluble Metals, and Oxidative Potential: A Link between Sulfate and Aerosol Toxicity, Environ. Sci. Technol., 51, 2611-2620, https://doi.org/10.1021/acs.est.6b06151, 2017.

Fountoukis, C. and Nenes, A.: ISORROPIA II: a computationally efficient thermodynamic equilibrium model for $\mathrm{K}^{+}-\mathrm{Ca}_{2}^{+}-\mathrm{Mg}_{2}^{+}-$ $\mathrm{NH}_{4}^{+}-\mathrm{Na}^{+}-\mathrm{SO}_{4}^{2-}-\mathrm{NO}_{3}-\mathrm{Cl}^{-}-\mathrm{H}_{2} \mathrm{O}$ aerosols, Atmos. Chem. Phys., 7, 4639-4659, https://doi.org/10.5194/acp-7-4639-2007, 2007.

Freedman, M. A.: Phase separation in organic aerosol, Chem. Soc. Rev., 46, 7694-7705, https://doi.org/10.1039/c6cs00783j, 2017.

Friese, E. and Ebel, A.: Temperature Dependent Thermodynamic Model of the System $\mathrm{H}^{+}-\mathrm{NH}_{4}^{+}-\mathrm{Na}^{+}-\mathrm{SO}_{4}^{2-} \mathrm{NO}_{3}^{-}$$\mathrm{Cl}^{-}-\mathrm{H}_{2} \mathrm{O}$, J. Phys. Chem. A, 114, 11595-11631, https://doi.org/10.1021/jp101041j, 2010.

Guo, H., Xu, L., Bougiatioti, A., Cerully, K. M., Capps, S. L., Hite Jr., J. R., Carlton, A. G., Lee, S.-H., Bergin, M. H., Ng, N. L., Nenes, A., and Weber, R. J.: Fine-particle water and $\mathrm{pH}$ in the southeastern United States, Atmos. Chem. Phys., 15, 5211-5228, https://doi.org/10.5194/acp-15-5211-2015, 2015.

Guo, H., Sullivan, A. P., Campuzano-Jost, P., Schroder, J. C., LopezHilfiker, F. D., Dibb, J. E., Jimenez, J. L., Thornton, J. A., Brown, S. S., Nenes, A., and Weber, R. J.: Fine particle pH and the partitioning of nitric acid during winter in the northeastern United States, J. Geophys. Res.-Atmos., 121, 10355-10376, https://doi.org/10.1002/2016JD025311, 2016.

Guo, H., Liu, J., Froyd, K. D., Roberts, J. M., Veres, P. R., Hayes, P. L., Jimenez, J. L., Nenes, A., and Weber, R. J.: Fine particle $\mathrm{pH}$ and gas-particle phase partitioning of inorganic species in Pasadena, California, during the 2010 CalNex campaign, Atmos. Chem. Phys., 17, 5703-5719, https://doi.org/10.5194/acp17-5703-2017, 2017.

Guo, H., Nenes, A., and Weber, R. J.: The underappreciated role of nonvolatile cations in aerosol ammoniumsulfate molar ratios, Atmos. Chem. Phys., 18, 17307-17323, https://doi.org/10.5194/acp-18-17307-2018, 2018a.

Guo, H., Otjes, R., Schlag, P., Kiendler-Scharr, A., Nenes, A., and Weber, R. J.: Effectiveness of ammonia reduction on control of fine particle nitrate, Atmos. Chem. Phys., 18, 12241-12256, https://doi.org/10.5194/acp-18-12241-2018, 2018b.

Gwynn, R. C., Burnett, R. T., and Thurston, G. D.: A time-series analysis of acidic particulate matter and daily mortality and morbidity in the Buffalo, New York, region, Environ. Health Persp., 108, 125-133, https://doi.org/10.2307/3454510, 2000.

Hallquist, M., Wenger, J. C., Baltensperger, U., Rudich, Y., Simpson, D., Claeys, M., Dommen, J., Donahue, N. M., George, C., Goldstein, A. H., Hamilton, J. F., Herrmann, H., Hoffmann, T., Iinuma, Y., Jang, M., Jenkin, M. E., Jimenez, J. L., Kiendler-Scharr, A., Maenhaut, W., McFiggans, G., Mentel, Th. F., Monod, A., Prévôt, A. S. H., Seinfeld, J. H., Surratt, J. D., Szmigielski, R., and Wildt, J.: The formation, properties and impact of secondary organic aerosol: current and emerging issues, Atmos. Chem. Phys., 9, 5155-5236, https://doi.org/10.5194/acp9-5155-2009, 2009.

Hennigan, C. J. and Battaglia Jr., M. A.: Thermodynamic modeling of WSOC effects on aerosol pH, Knowledge Network for Bio- 
complexity, urn:uuid:ae58e5f1-fb13-4e9c-800b-eeb8bcb14d84, 2019.

Hennigan, C. J., Izumi, J., Sullivan, A. P., Weber, R. J., and Nenes, A.: A critical evaluation of proxy methods used to estimate the acidity of atmospheric particles, Atmos. Chem. Phys., 15, 27752790, https://doi.org/10.5194/acp-15-2775-2015, 2015.

Huang, R.-J., Zhang, Y., Bozzetti, C., Ho, K.-F., Cao, J.-J., Han, Y., Daellenbach, K. R., Slowik, J. G., Platt, S. M., Canonaco, F., Zotter, P., Wolf, R., Pieber, S. M., Bruns, E. A., Crippa, M., Ciarelli, G., Piazzalunga, A., Schwikowski, M., Abbaszade, G., SchnelleKreis, J., Zimmermann, R., An, Z., Szidat, S., Baltensperger, U., El Haddad, I., and Prevot, A. S. H.: High secondary aerosol contribution to particulate pollution during haze events in China, Nature, 514, 218-222, https://doi.org/10.1038/nature13774, 2014.

Jacobson, M. Z.: Studying the effects of calcium and magnesium on size-distributed nitrate and ammonium with EQUISOLV II, Atmos. Environ., 33, 3635-3649, https://doi.org/10.1016/S13522310(99)00105-3, 1999

Jia, S., Wang, X., Zhang, Q., Sarkar, S., Wu, L., Huang, M., Zhang, J., and Yang, L.: Technical note: Comparison and interconversion of $\mathrm{pH}$ based on different standard states for aerosol acidity characterization, Atmos. Chem. Phys., 18, 11125-11133, https://doi.org/10.5194/acp-18-11125-2018, 2018.

Johnson, A. H., Moyer, A., Bedison, J. E., Richter, S. L., and Willig, S. A.: Seven Decades of Calcium Depletion in Organic Horizons of Adirondack Forest Soils, Soil Sci. Soc. Am. J., 72, 1824-1830, https://doi.org/10.2136/sssaj2006.0407, 2008.

Kanakidou, M., Myriokefalitakis, S., Daskalakis, N., Fanourgakis, G., Nenes, A., Baker, A. R., Tsigaridis, K., and Mihalopoulos, N.: Past, Present, and Future Atmospheric Nitrogen Deposition, J. Atmos. Sci., 73, 2039-2047, https://doi.org/10.1175/jas-d-150278.1, 2016.

Kawamura, K. and Bikkina, S.: A review of dicarboxylic acids and related compounds in atmospheric aerosols: Molecular distributions, sources and transformation, Atmos. Res., 170, 140-160, https://doi.org/10.1016/j.atmosres.2015.11.018, 2016.

Keene, W. C., Sander, R., Pszenny, A. A. P., Vogt, R., Crutzen, P. J., and Galloway, J. N.: Aerosol pH in the marine boundary layer: A review and model evaluation, J. Aerosol Sci., 29, 339-356, https://doi.org/10.1016/S0021-8502(97)10011-8, 1998.

Keene, W. C., Pszenny, A. A. P., Maben, J. R., Stevenson, E., and Wall, A.: Closure evaluation of size-resolved aerosol $\mathrm{pH}$ in the New England coastal atmosphere during summer, J. Geophys. Res.-Atmos., 109, D23307, https://doi.org/10.1029/2004jd004801, 2004.

Keppel, G.: Design and Analysis: A Researcher's Handbook, 3rd ed., Prentice-Hall, Inc., Englewood Cliffs, NJ, US, 1991.

Kim, Y. P. and Seinfeld, J. H.: Atmospheric Gas-Aerosol Equilibrium 3. Thermodynamics of Crustal Elements $\mathrm{Ca}^{2+}, \mathrm{K}^{+}$, and $\mathrm{Mg}^{2+}$, Aerosol Sci. Tech., 22, 93-110, https://doi.org/10.1080/02786829408959730, 1995.

Lide, D. R. (Ed.): CRC Handbook of Chemistry and Physics, 75th Edition CRC Press, Inc. Ann Arbor, MI, 1994

Myriokefalitakis, S., Nenes, A., Baker, A. R., Mihalopoulos, N., and Kanakidou, M.: Bioavailable atmospheric phosphorous supply to the global ocean: a 3-D global modeling study, Biogeosciences, 13, 6519-6543, https://doi.org/10.5194/bg-13-6519-2016, 2016.

Myriokefalitakis, S., Ito, A., Kanakidou, M., Nenes, A., Krol, M. C., Mahowald, N. M., Scanza, R. A., Hamilton, D. S., Johnson, M.
S., Meskhidze, N., Kok, J. F., Guieu, C., Baker, A. R., Jickells, T. D., Sarin, M. M., Bikkina, S., Shelley, R., Bowie, A., Perron, M. M. G., and Duce, R. A.: Reviews and syntheses: the GESAMP atmospheric iron deposition model intercomparison study, Biogeosciences, 15, 6659-6684, https://doi.org/10.5194/bg-15-66592018, 2018.

Nah, T., Guo, H., Sullivan, A. P., Chen, Y., Tanner, D. J., Nenes, A., Russell, A., Ng, N. L., Huey, L. G., and Weber, R. J.: Characterization of aerosol composition, aerosol acidity, and organic acid partitioning at an agriculturally intensive rural southeastern US site, Atmos. Chem. Phys., 18, 11471-11491, https://doi.org/10.5194/acp-18-11471-2018, 2018.

Nenes, A., Krom, M. D., Mihalopoulos, N., Van Cappellen, P., Shi, Z., Bougiatioti, A., Zarmpas, P., and Herut, B.: Atmospheric acidification of mineral aerosols: a source of bioavailable phosphorus for the oceans, Atmos. Chem. Phys., 11, 6265-6272, https://doi.org/10.5194/acp-11-6265-2011, 2011.

Peters, A., Goldstein, I. F., Beyer, U., Franke, K., Heinrich, J., Dockery, D. W., Spengler, J. D., and Wichmann, H. E.: Acute health effects of exposure to high levels of air pollution in eastern Europe, Am. J. Epidemiol., 144, 570-581, 1996.

Pye, H. O. T., Zuend, A., Fry, J. L., Isaacman-VanWertz, G., Capps, S. L., Appel, K. W., Foroutan, H., Xu, L., Ng, N. L., and Goldstein, A. H.: Coupling of organic and inorganic aerosol systems and the effect on gas-particle partitioning in the southeastern US, Atmos. Chem. Phys., 18, 357-370, https://doi.org/10.5194/acp18-357-2018, 2018.

Rindelaub, J. D., Craig, R. L., Nandy, L., Bondy, A. L., Dutcher, C. S., Shepson, P. B., and Ault, A. P.: Direct Measurement of $\mathrm{pH}$ in Individual Particles via Raman Microspectroscopy and Variation in Acidity with Relative Humidity, J. Phys. Chem. A, 120, 911917, https://doi.org/10.1021/acs.jpca.5b12699, 2016.

Robinson, R. A. and Stokes, R. H.: Electrolyte solutions, 2nd revised ed., Butterworths, London, 1965.

Schindler, D. W.: Effects of acid rain on freshwater ecosystems, Science, 239, 149-157, https://doi.org/10.1126/science.239.4836.149, 1988.

Seinfeld, J. H. and Pandis, S. N.: Atmospheric chemistry and physics: from air pollution to climate change, 3 ed., John Wiley \& Sons, Hoboken, 2016

Song, M., Ham, S., Andrews, R. J., You, Y., and Bertram, A. K.: Liquid-liquid phase separation in organic particles containing one and two organic species: importance of the average O:C, Atmos. Chem. Phys., 18, 12075-12084, https://doi.org/10.5194/acp-18-12075-2018, 2018a.

Song, S., Gao, M., Xu, W., Shao, J., Shi, G., Wang, S., Wang, Y., Sun, Y., and McElroy, M. B.: Fine-particle $\mathrm{pH}$ for Beijing winter haze as inferred from different thermodynamic equilibrium models, Atmos. Chem. Phys., 18, 7423-7438, https://doi.org/10.5194/acp-18-7423-2018, 2018b.

Spengler, J. D., Koutrakis, P., Dockery, D. W., Raizenne, M., and Speizer, F. E.: Health effects of acid aerosols on North American children: Air pollution exposures, Environ. Health Persp., 104, 492-499, https://doi.org/10.2307/3432989, 1996.

Tan, T. Y., Hu, M., Li, M. R., Guo, Q. F., Wu, Y. S., Fang, X., Gu, F. T., Wang, Y., and Wu, Z. J.: New insight into PM2.5 pollution patterns in Beijing based on one-year measurement of chemical compositions, Sci. Total Environ., 621, 734-743, https://doi.org/10.1016/j.scitotenv.2017.11.208, 2018. 
Trebs, I., Metzger, S., Meixner, F. X., Helas, G. N., Hoffer, A., Rudich, Y., Falkovich, A. H., Moura, M. A. L., da Silva, R. S., Artaxo, P., Slanina, J., and Andreae, M. O.: The $\mathrm{NH}_{4}^{+}-\mathrm{NO}_{3}^{-}$$\mathrm{Cl}^{-}-\mathrm{SO}_{4}^{2-}-\mathrm{H}_{2} \mathrm{O}$ aerosol system and its gas phase precursors at a pasture site in the Amazon Basin: how relevant are mineral cations and soluble organic acids?, J. Geophys. Res.-Atmos., 110, D07303, https://doi.org/10.1029/2004JD005478, 2005.

Vasilakos, P., Russell, A., Weber, R., and Nenes, A.: Understanding nitrate formation in a world with less sulfate, Atmos. Chem. Phys., 18, 12765-12775, https://doi.org/10.5194/acp-18-127652018, 2018.

Wang, G., Zhang, R., Gomez, M. E., Yang, L., Levy Zamora, M., Hu, M., Lin, Y., Peng, J., Guo, S., Meng, J., Li, J., Cheng, C., Hu, T., Ren, Y., Wang, Y., Gao, J., Cao, J., An, Z., Zhou, W., Li, G., Wang, J., Tian, P., Marrero-Ortiz, W., Secrest, J., Du, Z., Zheng, J., Shang, D., Zeng, L., Shao, M., Wang, W., Huang, Y., Wang, Y., Zhu, Y., Li, Y., Hu, J., Pan, B., Cai, L., Cheng, Y., Ji, Y., Zhang, F., Rosenfeld, D., Liss, P. S., Duce, R. A., Kolb, C. E., and Molina, M. J.: Persistent sulfate formation from London Fog to Chinese haze, P. Natl. Acad. Sci. USA, 113, 13630-13635, https://doi.org/10.1073/pnas.1616540113, 2016.

Weber, R. J., Guo, H., Russell, A. G., and Nenes, A.: High aerosol acidity despite declining atmospheric sulfate concentrations over the past 15 years, Nat. Geosci., 9, 282-285, https://doi.org/10.1038/ngeo2665, 2016.

Wexler, A. S. and Clegg, S. L.: Atmospheric aerosol models for systems including the ions $\mathrm{H}^{+}, \mathrm{NH}_{4}^{+}, \mathrm{Na}^{+}, \mathrm{SO}_{4}^{2-}$, $\mathrm{NO}_{3}^{-}, \mathrm{Cl}^{-}, \mathrm{Br}^{-}$, and $\mathrm{H}_{2} \mathrm{O}$, J. Geophys. Res.-Atmos., 107, 4207, https://doi.org/10.1029/2001jd000451, 2002.

Xu, L., Guo, H. Y., Boyd, C. M., Klein, M., Bougiatioti, A., Cerully, K. M., Hite, J. R., Isaacman-VanWertz, G., Kreisberg, N. M., Knote, C., Olson, K., Koss, A., Goldstein, A. H., Hering, S. V., de Gouw, J., Baumann, K., Lee, S. H., Nenes, A., Weber, R. J., and $\mathrm{Ng}$, N. L.: Effects of anthropogenic emissions on aerosol formation from isoprene and monoterpenes in the southeastern United States, P. Natl. Acad. Sci. USA, 112, 37-42, https://doi.org/10.1073/pnas.1417609112, 2015.
Yatavelli, R. L. N., Mohr, C., Stark, H., Day, D. A., Thompson, S. L., Lopez-Hilfiker, F. D., Campuzano-Jost, P., Palm, B. B., Vogel, A. L., Hoffmann, T., Heikkinen, L., Aijala, M., Ng, N. L., Kimmel, J. R., Canagaratna, M. R., Ehn, M., Junninen, H., Cubison, M. J., Petaja, T., Kulmala, M., Jayne, J. T., Worsnop, D. R., and Jimenez, J. L.: Estimating the contribution of organic acids to northern hemispheric continental organic aerosol, Geophys. Res. Lett., 42, 6084-6090, https://doi.org/10.1002/2015gl064650, 2015.

You, Y., Renbaum-Wolff, L., and Bertram, A. K.: Liquid-liquid phase separation in particles containing organics mixed with ammonium sulfate, ammonium bisulfate, ammonium nitrate or sodium chloride, Atmos. Chem. Phys., 13, 11723-11734, https://doi.org/10.5194/acp-13-11723-2013, 2013.

Zhou, W., Wang, Q., Zhao, X., Xu, W., Chen, C., Du, W., Zhao, J., Canonaco, F., Prévôt, A. S. H., Fu, P., Wang, Z., Worsnop, D. R., and Sun, Y.: Characterization and source apportionment of organic aerosol at $260 \mathrm{~m}$ on a meteorological tower in Beijing, China, Atmos. Chem. Phys., 18, 3951-3968, https://doi.org/10.5194/acp-18-3951-2018, 2018.

Zuend, A. and Seinfeld, J. H.: Modeling the gas-particle partitioning of secondary organic aerosol: the importance of liquidliquid phase separation, Atmos. Chem. Phys., 12, 3857-3882, https://doi.org/10.5194/acp-12-3857-2012, 2012.

Zuend, A., Marcolli, C., Luo, B. P., and Peter, T.: A thermodynamic model of mixed organic-inorganic aerosols to predict activity coefficients, Atmos. Chem. Phys., 8, 4559-4593, https://doi.org/10.5194/acp-8-4559-2008, 2008.

Zuend, A., Marcolli, C., Booth, A. M., Lienhard, D. M., Soonsin, V., Krieger, U. K., Topping, D. O., McFiggans, G., Peter, T., and Seinfeld, J. H.: New and extended parameterization of the thermodynamic model AIOMFAC: calculation of activity coefficients for organic-inorganic mixtures containing carboxyl, hydroxyl, carbonyl, ether, ester, alkenyl, alkyl, and aromatic functional groups, Atmos. Chem. Phys., 11, 9155-9206, https://doi.org/10.5194/acp-11-9155-2011, 2011. 